\title{
Stomatal movements and gas exchanges of a triticale and its parental species in water-stress conditions
}

\author{
A Morant-Avice $^{1 \star}, \mathrm{P}_{\text {Jurvilliers }}{ }^{1}$, A Coudret $^{2}$ \\ ${ }^{1}$ Laboratoire de Physiologie Végétale, Université du Maine, BP 535, F72017 Le Mans Cedex; \\ ${ }^{2}$ Laboratoire de Physiologie et Biotechnologies Végétales, Université Blaise-Pascal, 4, rue Ledru, \\ F63038 Clermont-Ferrand Cedex, France
}

(Received 7 July 1993; accepted 6 December 1993)

\begin{abstract}
Summary - The triticale T300 and its parental species (Triticum dicoccum farrum and Secale cereale $\mathrm{cr}$ 'Petkus') were subjected to transient and prolonged osmotic stress in order to define their adaptative capacities to arid environments. First, a transient osmotic stress was induced by a rapid replacement of the nutrient solution by another complemented with $86 \mathrm{mM} \mathrm{NaCl}$ or $61 \mathrm{mM} \mathrm{PEG}$, the shoot placed in air at $33.5 \%$ or $47 \%$ relative humidity. Water fluxes then decreased according to the species and stress conditions. Under prolonged water stress in presence of $61 \mathrm{mM} P E G$ in the nutrient medium, Triticum df had a better water-use efficiency than T300 and rye. On the contrary, in the nutrient solution, T300 had a better water-use efficiency than its parental species. Under water stress, water loss was avoided by stomatal closure in rye and Triticum df, whereas in T 300 the stomata stayed open and gas exchange were lower than in control plants.
\end{abstract}

stomata / water-use efficiency / osmotic stress / triticale

Résumé - Mouvements stomatiques et échanges gazeux d'un triticale et de ses espèces parentales en conditions de stress hydrique. Le triticale $T 300$ et ses espèces parentales (Triticum dicoccum farrum et Secale cereale cv Petkus) ont été soumis à un choc osmotique transitoire ou de longue durée afin de préciser leurs capacités d'adaptation à un environnement aride. Le choc osmotique transitoire a été appliqué par remplacement rapide de la solution nutritive par une autre additionnée de $\mathrm{NaCl} 86 \mathrm{mM}$ ou de PEG $61 \mathrm{mM}$, les parties aériennes étant balayées par de l'air à $33,5 \%$ ou $47 \%$ d'humidité relative. Les flux d'eau sont alors plus ou moins diminués selon l'espèce et les conditions du stress. Par ailleurs ces céréales ont été cultivées en présence de PEG $61 \mathrm{mM}$. Dans ces conditions, Triticum df a une meilleure efficience de l'utilisation de l'eau que le triticale $T 300$ et le seigle. En revanche sur solution nutritive, le triticale T300 a une meilleure efficience que ses espèces parentales. En condition de stress hydrique, la transpiration est limitée par la fermeture des stomates chez le seigle et Triticum df ; en revanche les stomates de T 300 restent ouverts et les échanges gazeux sont plus faibles que chez les plantes témoins.

stomate / efficience de l'utilisation de l'eau / stress osmotique / triticale

\section{INTRODUCTION}

Hexaploid triticale has been considered as a new cereal with great potential particularly in marginal agricultural areas (Vermorel and Bernard, 1979). Because of its economic stake, numerous breeding programs have been undertaken (Hulse 1974; Cauderon, 1981) but the breakthrough for triticale is still awaited (Lelley, 1992). Particular attention should be paid to genotypes resistant to salinity and drought because very often saline

\footnotetext{
* Correspondence and reprints
} 
and drought conditions occur together. Preceding studies comparing triticales with others cereals, such as barley, durum wheat, soft wheat and rye under stress conditions are useful before any introduction and lead to contrasting results (Jensen and Jönssen, 1981; Mashhady et al, 1982; Touraine and Ammar, 1985; Gorham, 1990; Giunta et al, 1993; Josephides, 1993).

We have compared water fluxes, photosynthetic rate and stomatal aperture of a triticale and its parental species placed in stress conditions in order to establish some physiological responses of these cereals and drought resistance of the hybrid. Indeed, stomatal behavior of triticale has not been extensively reported in the literature. Therefore, stomata play a major role in gas exchange regulation between the plant and the atmosphere. First, the 3 cereals were submitted to transient osmotic stress (Morant-Avice et al, 1989) by addition of $\mathrm{NaCl}$ or polyethylene glycol (PEG) to the nutrient medium, the shoot being placed in air that is more or less dry. The water fluxes recorded permit the definition of an adaptative strategy of these plants to osmotic or ionic transient stress. We have also compared the water-use efficiency of these cereals grown in the presence of PEG as well as their stomatal aperture under maximal stomatal opening conditions in order to define, at an early stage, the behavior of these cereals under prolonged water stress.

\section{MATERIALS AND METHODS}

\section{Growth of plants}

The hexaploid triticale T $300(2 n=42$, genomes $A A B B R R$ ) is an amphiploid issued from hybridization between Triticum dicoccum farrum (Triticum df $(2 n=28$, genomes AA BB $)$ and Secale cereale cv 'Petkus' $(2 n=14$, genomes RR). Seeds were first supplied by $Y$ Cauderon (INRA, Versailles, France) and then by INRA Clermont Ferrand and INRA Guyancourt (France). They were germinated in Petri dishes in the presence of distilled water before transfer to hydroponic cultures in a phytotron. Seedlings were grown on nutrient medium (Coïc and Lesaint, 1973) with and without polyethylene glycol 1500 (PEG) $61 \mathrm{mM}$. The osmotic potential of the nutrient solution $\mathrm{M0}$ was $0.077 \mathrm{MPa}$ and that of the PEG solution was $-0.482 \mathrm{MPa}$. The photoperiod was $16 \mathrm{~h}$; the air temperature and water vapor pressure deficit were $22^{\circ} \mathrm{C}$ and $17.68 \mathrm{hPa}$ during the light period, $18^{\circ} \mathrm{C}$ and $10.30 \mathrm{hPa}$ during the dark period. The plants were illuminated with $400 \mathrm{~W}$ Phytoclaude lamps giving $280 \mu \mathrm{mol} \mathrm{m} \mathrm{m}^{-2} \mathrm{~s}^{-1}$ photosynthetic active radiation (PAR) at the collar level (LiCor, 400-700 nm).

\section{Experimental procedure}

After $12 \mathrm{~d}$, plants with 3-4 leaves were available in the experimental chamber and 18-d-old plants were used for porometry. In the 2 cases, the plants were placed in the measuring apparatus $20 \mathrm{~h}$ before the beginning of the experimentation.

Stomatal permeability was measured with a hydrogen porometer and is expressed in $\mathrm{cm}$ according to Louguet (1969). After $8 \mathrm{~h}$ in the dark, the aerial parts were submitted to the maximal stomatal opening treatment consisting of dry $\mathrm{CO}_{2}$-free air sweeping under illumination. Stomata closure was then obtained by extinction and return to ambient air.

Transpiration rate and net photosynthesis of a whole plant were continuously measured during $24 \mathrm{~h}$ in an experimental chamber (Lascève and Couchat, 1980) divided into 2 independent compartments for shoot and roots.

Plants were subjected to 2 kinds of stress:

(i) Plants cultivated on the nutrient solution were submitted to an osmotic root stress by rapid replacement of the root medium by another complemented with $86 \mathrm{mM} \mathrm{NaCl}$ or $61 \mathrm{mM}$ PEG (osmotic stress $=-0.40 \mathrm{MPa}$ ). These experiments were carried out under 33.5 or $47 \%$ relative humidity $(\mathrm{RH})$ in air corresponding to a water vapor pressure deficit of $17.55 \mathrm{hPa}$ and $14 \mathrm{hPa}$ at $22^{\circ} \mathrm{C}$, respectively; water fluxes were measured.

(ii) Plants were grown on the nutrient solution supplemented with PEG $61 \mathrm{mM}$ (+PEG). Daily rates of transpiration and net photosynthesis were recorded under $450 \mu \mathrm{mol} \mathrm{m} \mathrm{m}^{-2} \mathrm{~s}^{-1}$ PAR. The water vapor pressure deficit was $15.7 \mathrm{hPa}$ during the night period and $17.2 \mathrm{hPa}$ during the light period; stomatal movements were measured in the phytotron and compared with those of control plants grown on nutrient solution without additive.

The water-use efficiency was defined as net daily $C$ gain per unit of daily water lost (McCree and Richardson, 1987a).

Each experiment was repeated 3 times with different plants. The results presented in the figures correspond to a representative experiment from the 3 .

\section{RESULTS}

\section{Transient osmotic stress}

Whatever the osmotic stress and relative humidity, the transpiration rate of rye immedi- 
ately increased after the osmotic stress was applied, and then decreased gradually and became steady $2-3 \mathrm{~h}$ later at a lower level than before stress application (fig 1).

Under $33.5 \% \mathrm{RH}$, the transpiration of Triticum df decreased suddenly after the osmotic stress. On the contrary, under $47 \% \mathrm{RH}$ the decrease in osmotic potential of the nutrient solution induced a peak of transpiration (fig 2).

The triticale reacted to $\mathrm{NaCl}$ stress by a rapid and small increase in transpiration rate followed by a decrease. In contrast, PEG addition induced a strong decrease in transpiration under $47 \% \mathrm{RH}$ (fig 3 ).

In all cases, the water uptake rate followed the transpiration rate with a little delay (10 $\mathrm{min}$ ).

\section{Prolonged water stress}

Figure 4 shows that in rye grown in the presence of PEG has a decreased transpiration rate and an increased net photosynthesis rate in relation to control plants. The transpiration rate of Triticum $d f$ was reduced in the presence

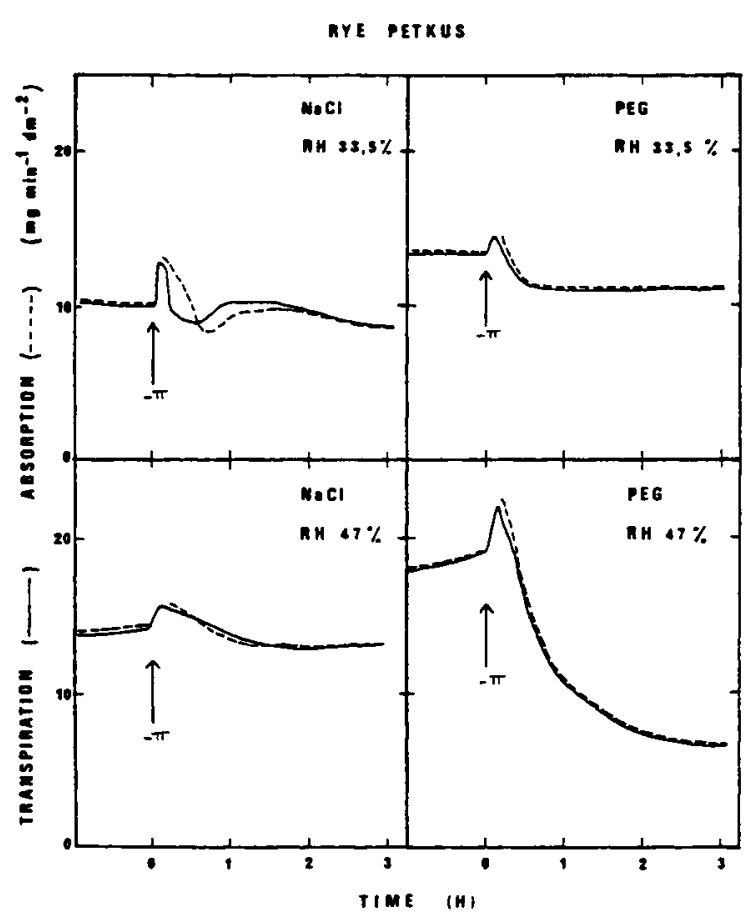

Fig 1. Transpiration and absorption rates of rye during osmotic stress ( $\mathrm{NaCl}$ or $\mathrm{PEG}$ ) under 33.5 or $47 \%$ air relative humidity; $-\Pi$, osmotic stress application.

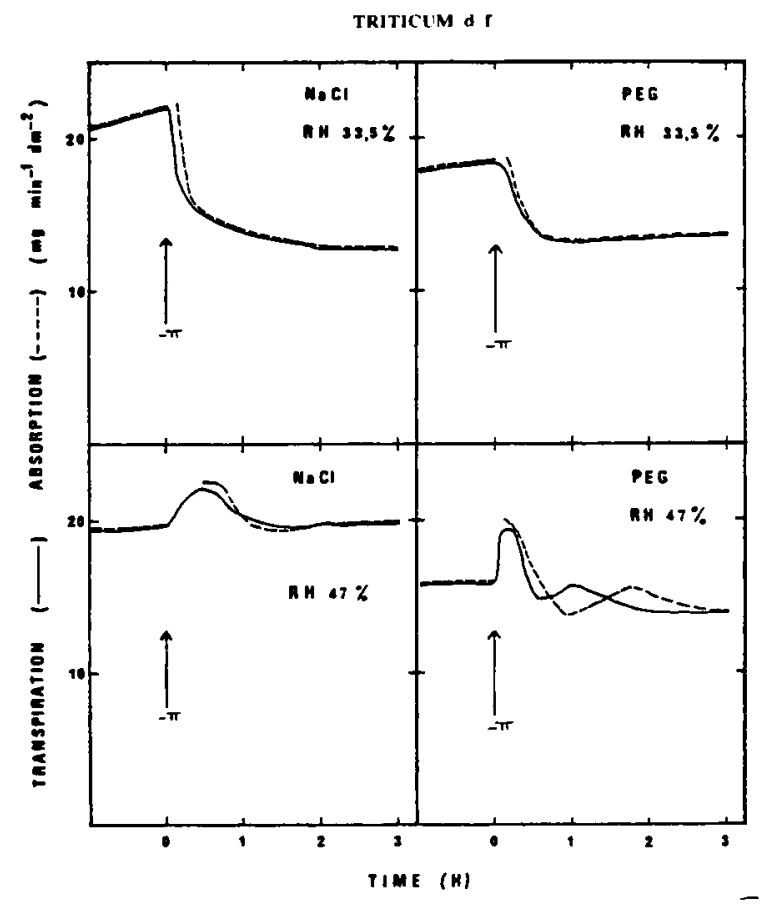

Fig. 2. Transpiration and absorption rates of Triticum $d f$ during osmotic stress ( $\mathrm{NaCl}$ or PEG) under 33.5 or $47 \%$ air relative humidity; $-\Pi$, osmotic stress application.

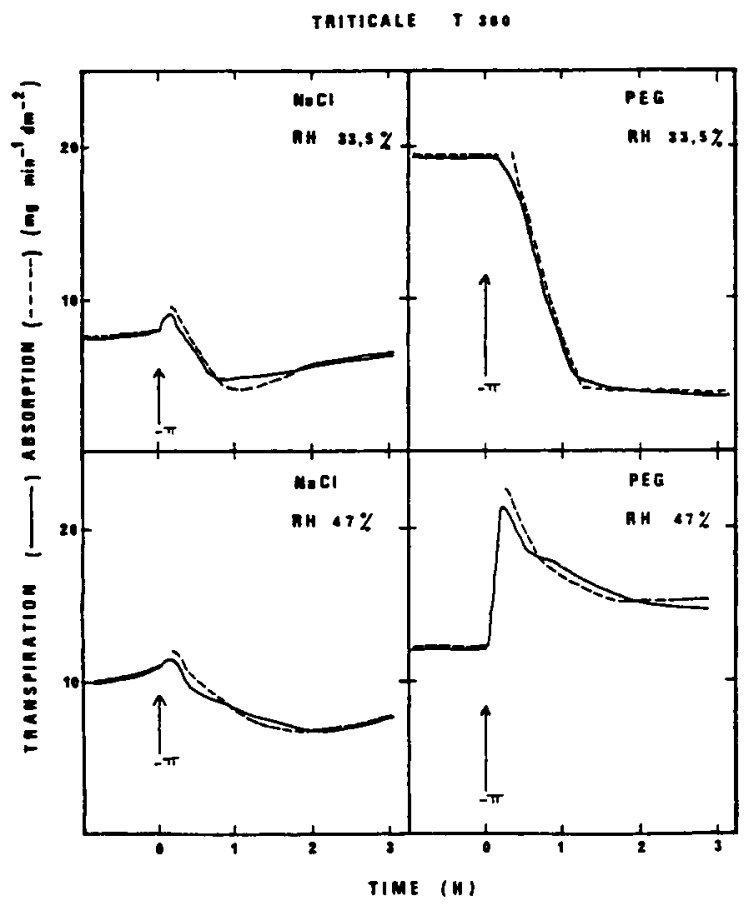

Fig. 3. Transpiration and absorption rates of $\mathrm{T} 300$ during osmotic stress ( $\mathrm{NaCl}$ or PEG) under 33.5 or $47 \%$ air relative humidity; $-\Pi$, osmotic stress application. 

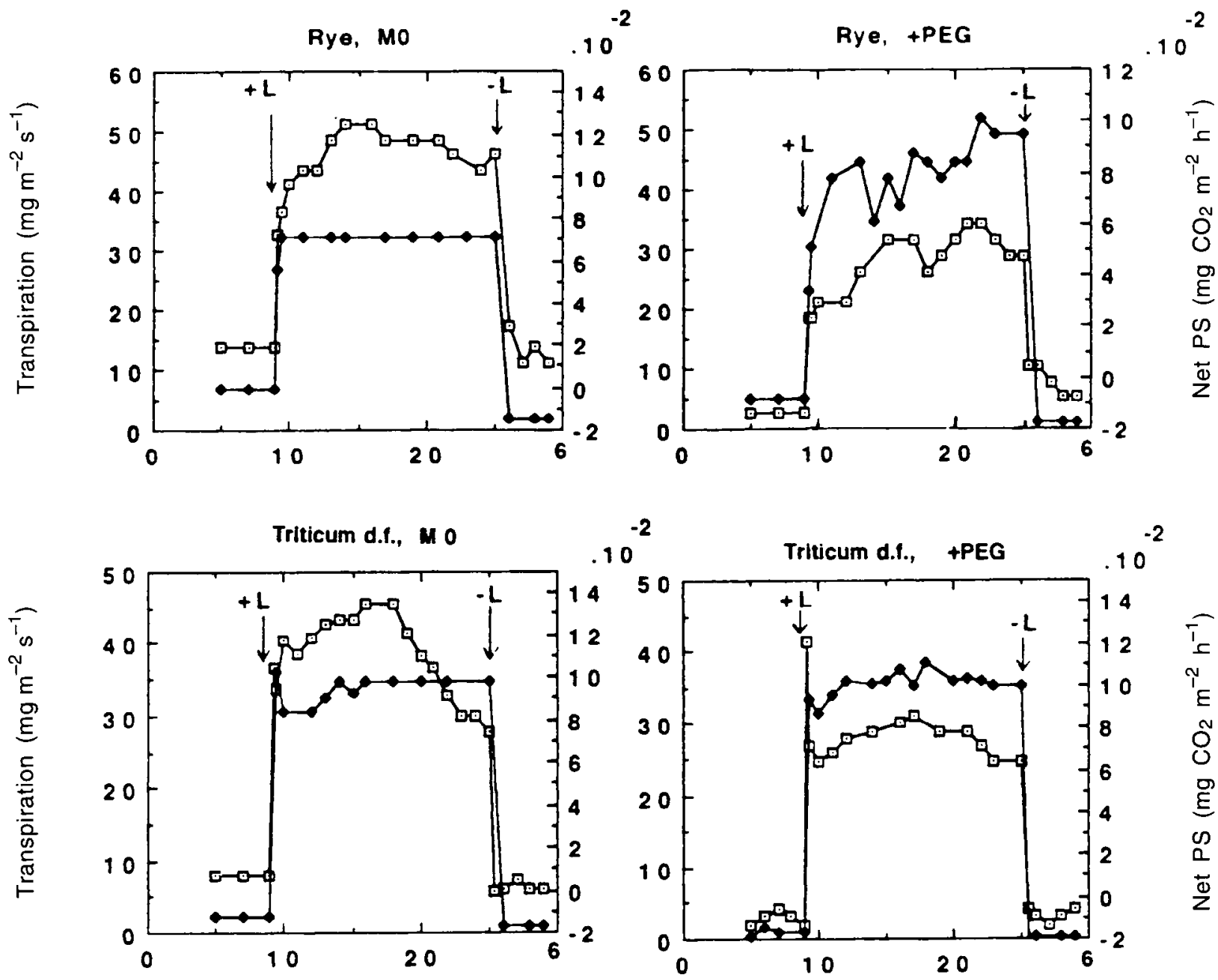

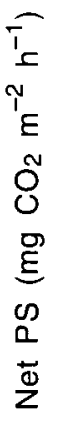

T 300, MO

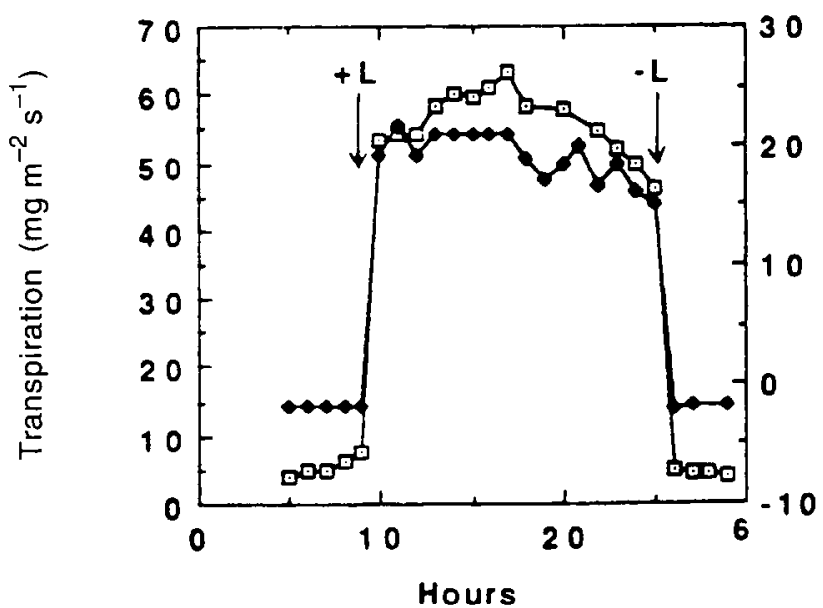

T 300, +PEG

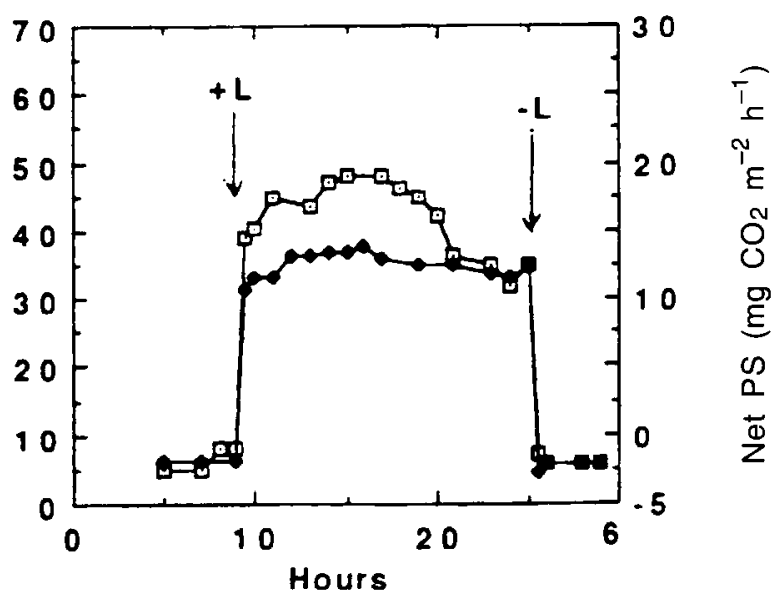

Fig. 4. Daily transpiration (--- $\square---)$ and photosynthesis ( ..- -.-) rates of rye, Triticum df and $T 300$ grown on nutrient medium (MO) or on nutrient medium complemented with PEG $(+P E G) ;+L$, light; $-L$, darkness.

of PEG compared with control plants on the nutrient medium (MO) but the net photosynthesis rates were similar in the 2 root mediums.
For the triticale, the addition of PEG to the nutrient solution induced a decrease in the transpiration and net photosynthesis rates. 
The water-use efficiency (fig 5) of the parental species was higher in plants grown in the presence of PEG than in controls. The water-use efficiency of T300 in the presence of PEG was slightly lower than in control plants. The comparative study of water-use efficiency of the 3 cereals grown on the 2 mediums is shown in figure 6 T300 > Triticum $d f>$ rye on the nutrient medium (M0) whereas Triticum $d f>\mathrm{T} 300>$ rye on this medium complemented with PEG(+ PEG).
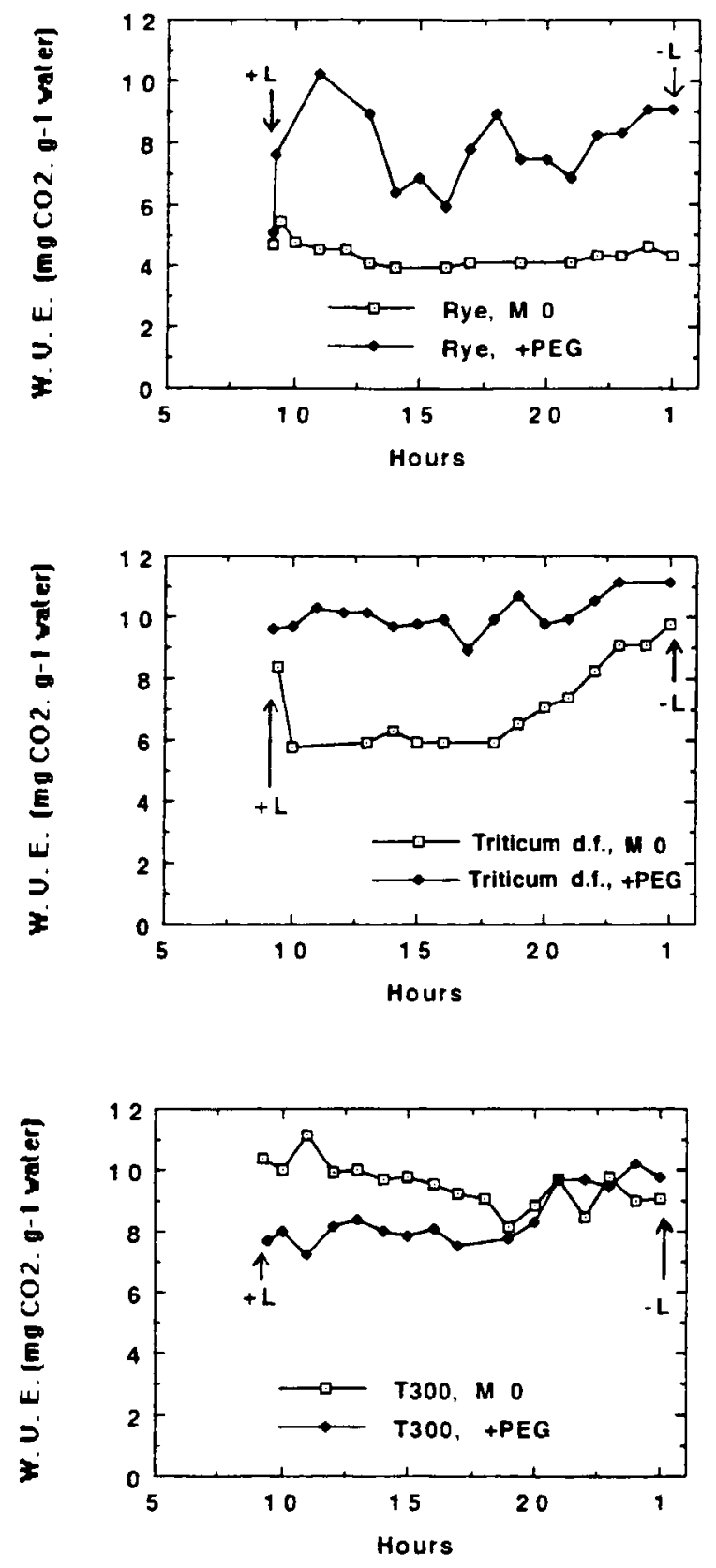

Fig. 5. Daily water-use efficiency (WUE) or rye, Triticum $d f$ and T 300 grown on MO or on +PEG; symbols as in figure 4 .
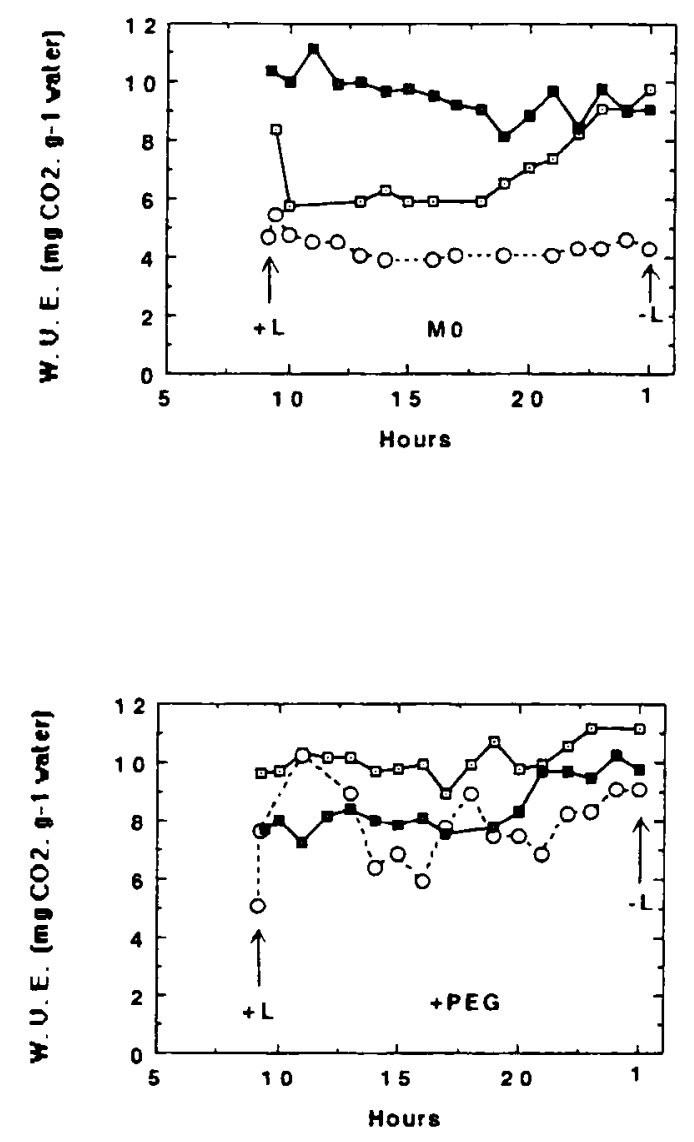

Fig. 6. Daily water-use efficiency (WUE) of rye, ( ... $\bigcirc$-..) Triticum df (--- $\square---)$ and T $300\left(---{ }^{---}\right)$grown on M0 or on + PEG; symbols as in figure 4 .

Finally, application of the maximal stomatal opening treatment (fig 7) showed that, in the presence of PEG, T 300 stomata stayed more open than those of its parental species, while on the nutrient solution without additive, the stomata of Triticum $d f$ stayed more open than those of rye and T300.

\section{DISCUSSION}

When our plants were submitted to transient osmotic stress, we observed 2 kinds of responses: a transient increase followed by a decrease in transpiration rate; or a fast decrease in transpiration rate. On the other hand, in 2 species of Plantago (Coudret et al, 1982) and in Triticum aestivum (Falk, 1966) osmotic stresses ( $\mathrm{NaCl}$ and or mannitol) always induced a transient increase of transpiration rate due to a transient stomatal 
Rye, $\mathbf{M} 0$

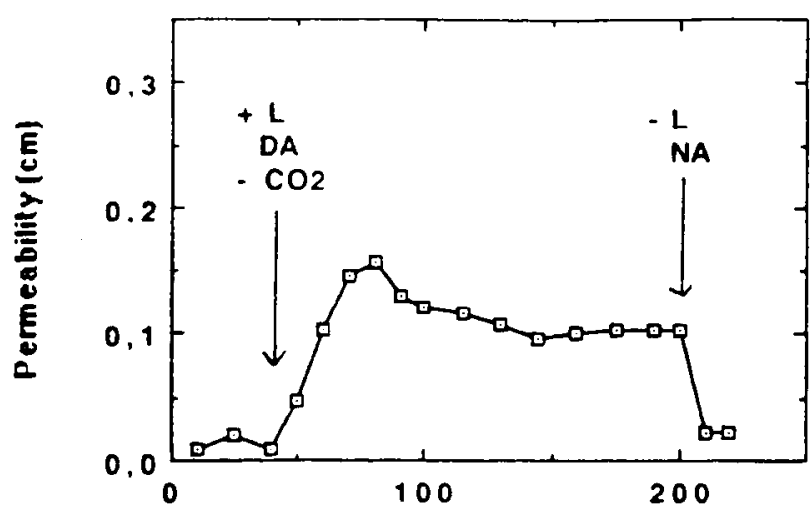

Triticum d.I., M 0

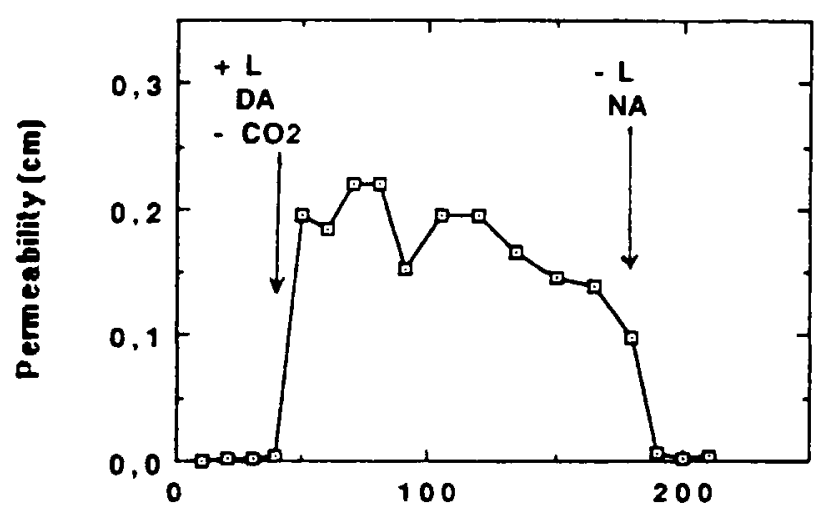

T300, $\mathrm{Mo}$

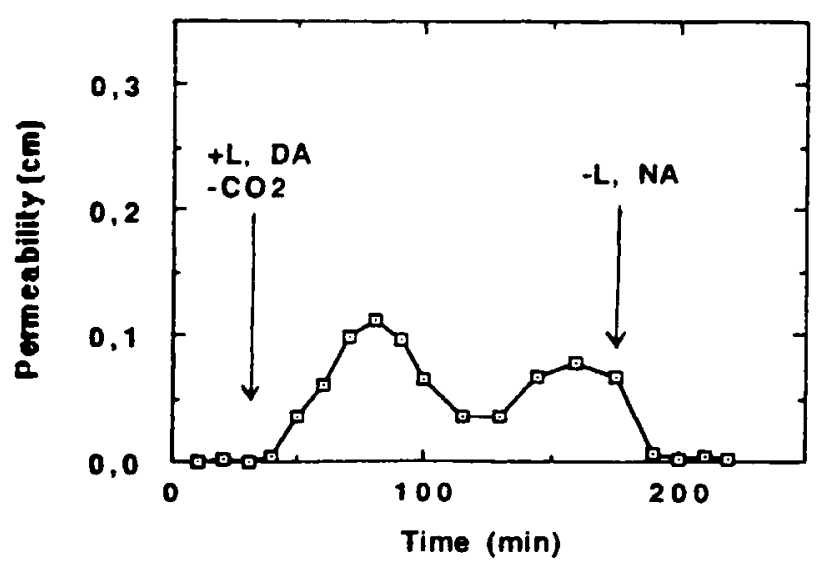

Rye, +PEG

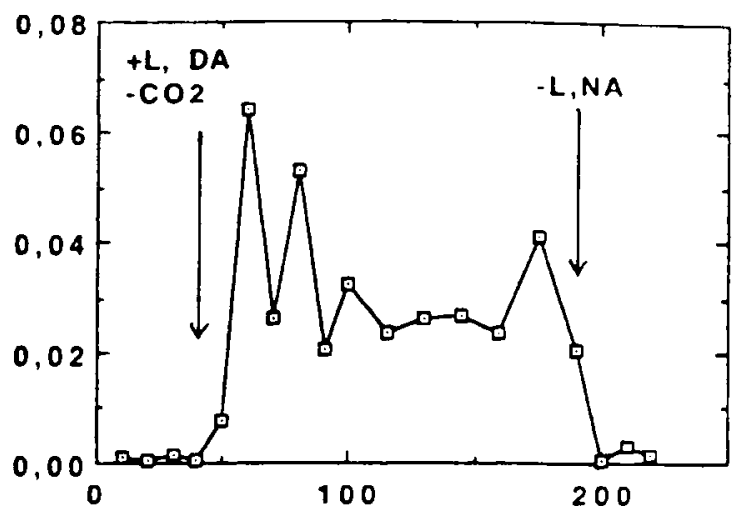

Triticum d.t., +PEG

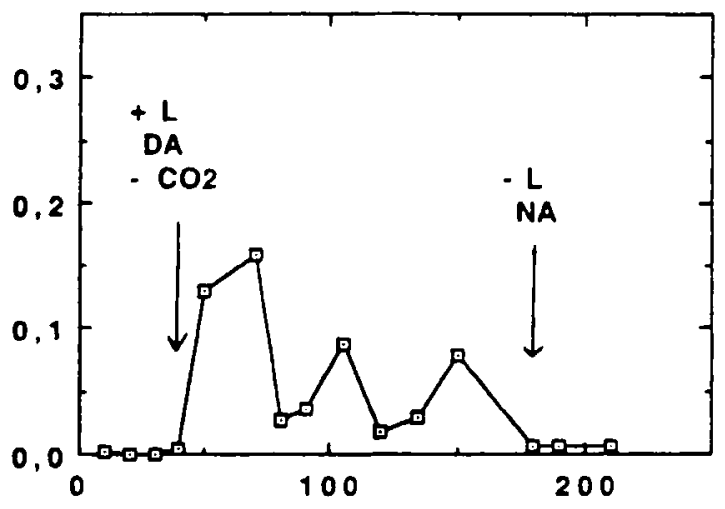

T 300, +PEG

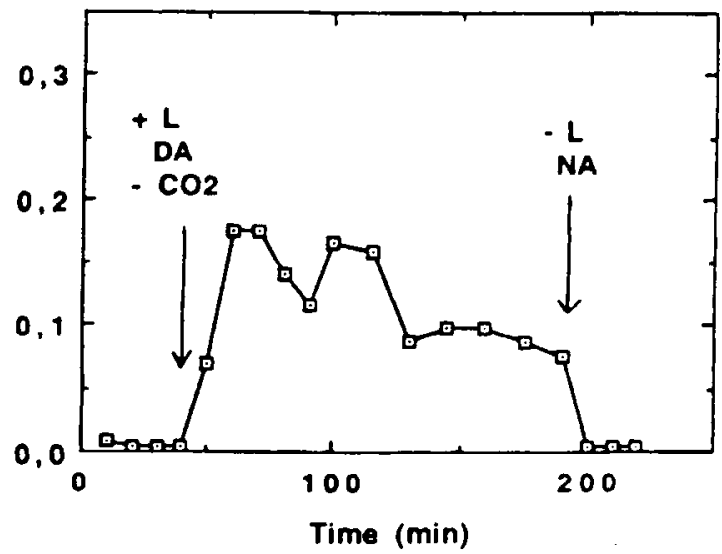

Fig. 7. Stomatal permeability of rye, Triticum $d f$ and $T 300$ grown on $M 0$ or on + PEG during maximal stomatal opening treatment as a function of time; DA, dry air; NA, normal air; no $\mathrm{CO}_{2} ; \mathrm{CO}_{2}$-free air; symbols as in figure 2 .

supraopening, the transpiration flux being closely related to the stomatal aperture. PEG osmotic stress also induced a transient increase of transpiration rate followed by a stomatal closure in pinto bean leaf discs (Heath et al, 1985). After the application of osmotic stress, the water uptake capacity of the 3 cereals studied was closely related to water loss by transpiration. In the presence of $\mathrm{NaCl}$, water fluxes of rye and T300 seemed less disturbed than in the presence of PEG; $\mathrm{NaCl}$ should be absorbed and contribute to osmotic 
adjustment and reduce the osmotic stress. Considering the short time $(4-8 \mathrm{~min})$ of stomatal response and the $\mathrm{O}_{2}$ dependence of stomatal supraopening to transient osmotic stress (Morant-Avice and Coudret, 1992), a root signal was proposed. On the other hand the Triticum df response should be more $\mathrm{RH}$ than osmotic-nature dependent. Stomatal closure avoids dessication and allows the maintenance of leaf water potential at a high level. A prolonged water stress in the presence of PEG induced a decrease of the daily transpiration rate of all 3 cereals in relation to control plants. Similar results have been obtained in Triticum aestivum (Simmelsgaard, 1976) and in Avena sativa (Brogardh et al, 1974; Svenningsson and Liljenberg, 1986).

In contrast, net assimilation of $\mathrm{CO}_{2}$ varied according to plant. For Triticum df no significant difference was recorded, but the net photosynthesis rate of rye was increased and disturbed in the presence of PEG and that of $T 300$ was decreased in the presence of $P E G$ in relation to control plants.

The water-use efficiency corroborated the best primary productivity of the triticale on the nutrient medium but, under prolonged water stress, Triticum $d f$ had a better efficiency than rye and T300. An increase of water-use efficiency was also observed in Beta vulgaris, Vigna unguiculata and Sorghum bicolor under water stress in controlled environment conditions (McCree and Richardson, 1987b).

These results can be compared with stomatal aperture. On the nutrient medium, stomatal opening treatment reveals that stomatal aperture in Triticum df was larger than in rye and T300, but gas exchange and the wateruse efficiency were higher in T300 than in its parental species. As in Tradescantia virginiana (Nonami and Schulze, 1989), our results showed that transpiration and net $\mathrm{CO}_{2}$ assimilation rates and stomatal aperture were not linearly related to each other. In the presence of PEG, Triticum df and particularly rye avoided dehydratation by closing stomata but net $\mathrm{CO}_{2}$ assimilation decreased only slighty (water-use efficiency then increased). Water loss in T300 does not seem be regulated by stomata, and foliar turgor potential should be maintained by osmoticum synthesis as in Triticum aestivum grown in the presence of PEG (Simmelsgaard, 1976) or in Beta vulgaris after interruption of soil irrigation (McCree and Richardson, 1987a). Further experiments should be necessary to confirm the proposed adaptative strategies: that the rye 'Petkus' and Triticum df should have sensitive stomata that avoid dessication; and T300 keeps stomata open and should maintain turgor by osmotic adjustment. Water stress should also decrease cuticular transpiration as Svenningsson and Liljenberg (1986) have shown in oat. Considering the water-use efficiency in the presence of PEG, the drought-resistant character is not expressed by T 300 . Study of the yield and grain quality of T300 under water stress will help evaluate the agronomic value of this hybrid in drought soil.

\section{REFERENCES}

Brogardh T, Johnson A, Klockare R (1974) Oscillatory transpiration and water uptake of Avena plants. V. Influence of the water potential of the root medium. Physiol Plant 32, 258-267

Cauderon $Y$ (1981) Origine et évolution des triticales. Industries des céréales 10, 3-9

Coic $Y$, Lesaint C (1973) La nutrition minérale en horticulture avancée. Rev Hort 2316, 29-34

Coudret A, Férard G, Lascève G (1982) Choc osmotique et mouvements d'eau chez Plantago. Physiol Veg 20, 711-720

Falk SO (1966) Effect on transpiration and water uptake by rapid changes in the osmotic potential of the nutrient solution. Physiol Plant 19, 602-617

Giunta F, Motzo R, Deidda M (1993) Effect of drought on yield and yield components of durum wheat and triticale in a Mediterranean environment. Field Crops Res 33, 399-409

Gorham J (1990) Salt tolerance in the triticeae: ion discrimination in rye and triticale. $J$ Exp Bot $41,609-614$

Heath RL, Furbank RT, Walker DA (1985) Effects of polyethylene glycol induced osmotic stress on transpiration and photosynthesis in Pinto bean leaf discs. Plant Physiol 78, 627-629

Hulse JH (1974) Contre la faim dans le monde: le projet triticale. La Recherche 5, 188-190

Jensen P, Jönsson AS (1981) Heterosis and ion transport in hexaploid varieties of rye-wheat (triticale) compared to the parental species. Physiol Plant 53, 342-346

Josephides CM (1993) Analysis of adaptation of barley, triticale, durum and bread wheat under Mediterranean conditions. Euphytica 65, 1-8

Lascève G, Couchat P (1980) Le transfert de l'eau dans une plante en régime transitoire. Ann Agron 31, 273-283 
Lelley T (1992) Triticale, still a promise? Plant Breeding 109, 1-17

Louguet $P$ (1969) Détermination du mode d'expression de la vitesse du mouvement des stomates chez le Pelargonium $X$ hortorum. CR Acad Sci Paris 269, 1777-1780

Mashhady AS, Sayed HI, Heakal MS (1982) Effect of soil salinity and water stresses on growth and content of nitrogen, chloride and phosphate of wheat and triticale. Plant soil 68, 207216

McCree KJ, Richardson SG (1987a) Stomatal closure vs osmotic adjustment: a comparison of stress response. Crop Sci 27, 539-543

McCree KJ, Richardson SG (1987b) Salt increases the water-use efficiency in waterstressed plants. Crop Sci 27, 543-547

Morant-Avice A, Férard G, Coudret A (1989) Effect of osmotic stress on transpiration and absorption rates in triticale and its parental species. Biol Plant 31, 241-246
Morant-Avice A, Coudret A (1992) Transpiration variations of Secale cereale to osmotic stress under anoxia and partial pressure of $\mathrm{CO}_{2}$. Plant Physiol Biochem 30, 505-509

Nonami H, Schulze ED (1989) Cell water potential, osmotic potential, and turgor in epidermis and mesophyll transpiring leaves. Planta $177,35-46$

Simmelsgaard SE (1976) Adaptation to water stress in wheat. Physiol Plant 37, 167-174

Svenningsson M, Liljenberg $C$ (1986) Changes in cuticular transpiration rate and cuticular lipids of oat (Avena sativa) seedlings induced by water stress. Physiol Plant 66, 9-14

Touraine B, Ammar M (1985) Étude comparée de la sensibilité au sel d'une triticale et d'une orge. agronomie 5, 391-395

Vermorel M, Bernard M (1979) Intérêt agronomique et nutritionnel du triticale. Bull Techn CR ZV, Theix, INRA 36, 31-42 